\title{
Girls' Disruptive Behavior and its Relationship to Family Functioning: A Review
}

\author{
Leoniek M. Kroneman • Rolf Loeber • \\ Alison E. Hipwell $\cdot$ Hans M. Koot
}

Published online: 5 August 2008

(c) The Author(s) 2008. This article is published with open access at Springerlink.com

\begin{abstract}
Although a number of reviews of gender differences in disruptive behavior and parental socialization exist, we extend this literature by addressing the question of differential development among girls and by placing both disruptive behavior and parenting behavior in a developmental framework. Clarifying the heterogeneity of development in girls is important for developing and optimizing gender-specific prevention and treatment programs. In the current review, we describe the unique aspects of the development of disruptive behavior in girls and explore how the gender-specific development of disruptive behavior can be explained by family linked risk and protective processes. Based on this review, we formulate a gender-specific reciprocal model of the influence of social factors on the development of disruptive behavior in girls in order to steer further research and better inform prevention and treatment programs.
\end{abstract}

Keywords Disruptive behavior · Girls . Family functioning $\cdot$ Child rearing practices

\section{Introduction}

Compared to boys, the study of explanatory factors of disruptive behavior in girls is underdeveloped. A number of major reviews have highlighted gender differences in

L. M. Kroneman $(\varangle) \cdot$ H. M. Koot

Department of Developmental Psychology, VU University, Van der Boechorststraat 1, 1081 BT Amsterdam, Netherlands e-mail: LM.Kroneman@psy.vu.nl

R. Loeber · A. E. Hipwell

Department of Psychiatry, School of Medicine,

University of Pittsburgh, Pittsburgh, PA, USA parental socialization, especially with regard to the development of disruptive behaviors (Crick and Zahn-Waxler 2003; Keenan and Shaw 1997; Lytton and Romney 1991; Zahn-Waxler and Polanichka 2004). While these prior reviews are of great value, they have not highlighted the key issue of explaining the differential development of disruptive behavior among girls. Clarifying the heterogeneity of development in girls, however, is important for developing and optimizing gender specific prevention and treatment programs. In this review we will first describe the phenotype and development of disruptive behavior in girls in childhood and adolescence. We will then review crosssectional and longitudinal studies examining the association between girls' disruptive behavior and family functioning. Subsequently we will explore how the genderspecific development of disruptive behavior can be explained by family linked risk and protective processes. Because girls tend to be more oriented towards interpersonal relationships and gaining social approval than boys (e.g. Gabriel and Gardner 1999; Maccoby 1990), it is possible that they may be especially vulnerable to the effects of, for example, low parental warmth and high levels of familial conflict.

Based on the research reviewed, we then propose a gender-specific family model of girls' development of disruptive behavior. Although we are aware of the influence of multiple risk factors in multiple domains, our primary goal is to review family processes in the development of girls' disruptive behavior. By necessity we will also refer to other risk factors of girls' development of disruptive behavior. We further add to the existing literature by placing both disruptive behavior and parenting behavior in a developmental context. We derive this framework partly from developmental psychopathology, i.e. the integration of research on normative development 
with that on psychopathology (see Cicchetti 1993). This framework allows for the exploration of developmental trajectories toward both positive and negative outcomes and, therefore, is equally focused on understanding the influence of risk and protective factors (Keenan and Shaw 1997).

\section{Phenotype and Development of Disruptive Behavior in Girls}

Phenotype

The term disruptive behavior is an overarching construct which has been variously used to describe oppositional behaviors, aggressive behavior, externalizing behaviors and delinquent acts. Childhood disruptive behavior is both concurrently and prospectively related to impaired functioning in many domains, such as social, emotional and academic (Rutter et al. 1998) and shows a remarkably high level of stability over time (e.g. Campbell 1995; Moffitt 1993; Lavigne et al. 1996; Offord et al. 1992). Also, childhood disruptive behavior is associated with negative outcomes in adulthood including delinquency, unemployment, substance use, mental health and parenting problems (Bardone et al. 1996; Chamberlain and Moore 2002; Lewis et al. 1991; Robins 1986; Serbin et al. 1991). Disruptive behavior is the most common problem behavior in children (Campbell 1995), with longitudinal and epidemiological studies consistently showing approximately $5-10 \%$ of boys and $1-3 \%$ of girls exhibiting serious conduct problems in childhood (Lavigne et al. 1996; Moffitt 1993). Despite the lower levels of disruptive behavior in girls compared to boys, clinic-referred samples of girls generally present with more severe behavior problems than boys (Kloosterman and Veerman 1997; Webster-Stratton 1996). Beginning in adolescence, girls are also more likely than boys to exhibit co-occurring symptoms and disorders (Costello et al. 2000; Costello et al. 2006), a phenomenon referred to as the 'gender-paradox' (e.g. Loeber and Keenan 1994; Robins 1986), indicating that the gender with the lesser prevalence of a certain disorder (in this case disruptive behavior) is at higher risk for additional negative outcomes which include drug abuse and mental health problems.

In addition to different prevalence rates in boys and girls, gender differences also exist in the phenotype of disruptive behavior (Keenan and Shaw 1997; Zoccolillo 1993), with most studies indicating that girls are more likely to display relational aggression whilst boys are more likely to show physical aggression (see review by Crick et al. 1999). Relational aggression is intended to harm relationships by, for example, threatening to withdraw acceptance or friendship, ostracizing, or using social exclusion or rumor spreading. Similar to physical aggression, relational aggression is associated with general externalizing problems and social-psychological maladjustment (e.g. Crick and Grotpeter 1995). Regarding characteristics of their delinquent behavior, girls compared to boys, demonstrate less overt physical aggression (e.g. Crick and Grotpeter 1995), are less often involved in gangs, street fighting and gun carrying (Esbensen et al. 1999), and are more likely to victimize family members than strangers in the course of their delinquent behavior (Heide 2003).

\section{Prevalence Rates of Girls’ Disruptive Behavior}

Reports of prevalence and developmental trajectories of disruptive behavior are likely to differ depending on the informants (parent, teacher, child) and the context (e.g. home, school) that they represent (Hipwell et al. 2002). Teachers have been found to report higher rates of disruptive behavior than parents (Hipwell et al. 2002; Keiley et al. 2000; Offord et al. 1989), which may be due to informant bias, differences in the meaning of the behaviors measured in each context and/or the instability of girls' behavior across settings (Hipwell et al. 2002). Furthermore, developmental studies of disruptive behavior also indicate different patterns of growth for specific disruptive behaviors (Tremblay 2000). For example, Bongers et al. (2004) showed that in girls, aggression, oppositional behavior and other problem behaviors such as cruelty to animals, lying/ cheating, firesetting, stealing and vandalism tended to decrease, whereas status violations (running away from home, swearing, truancy, alcohol or drug use) tended to increase over time.

\section{Rates of Disruptive Behavior in Childhood}

Using psychiatric nosology, large-scale representative community studies have reported prevalence rates of conduct disorder (CD) for girls during middle childhood ranging from $0.4 \%$ to $1.3 \%$. (Costello et al. 1996; Hipwell et al. 2002; Maughan et al. 2004) using various versions of the Diagnostic and Statistical Manual of Mental Disorders (DSM; American Psychiatric Association 1994). It should be noted, however, that the percentage of girls meeting formal diagnostic criteria (DSM-IV; APA 1994) in these studies may be an underestimate due to the fact that the formulation of diagnostic criteria in the DSM-IV for conduct disorder has been largely based on information about boys rather than girls. Scholars have therefore suggested the inclusion of 'female-sensitive' symptoms such as relational aggression (Crick and Grotpeter 1995; Crick et al. 2006; Galen and Underwood 1997; Xie et al. 2002) and indirect aggression (Bjorkqvist et al. 1992) in diagnostic criteria. 
For oppositional defiant disorder (ODD), epidemiological studies show prevalence rates for girls in childhood ranging from $1.1 \%$ to $9.4 \%$ (Breton et al. 1999; Kroes et al. 2001; Lahey et al. 2000; Simonoff et al. 1997).

Epidemiological studies show that the highest levels of disruptive behavior in both girls and boys occur during the preschool period (e.g., Alink et al. 2006; Tremblay 2001). At that age, children are still developing their communication and social skills and often rely on aggressive and oppositional behavior to respond to or to control their social environment (Tremblay 2000). Problem behaviors at this age generally consist of temper tantrums, aggression and non-compliance. Among preschoolers, there appear to be relatively few gender differences in the presentation of disruptive behaviors (e.g. Keenan and Shaw 1997; Webster-Stratton 1996).

A small, albeit growing, body of research is accumulating regarding girls' developmental trajectories of disruptive behavior in (middle) childhood (Broidy et al. 2003; Côté et al. 2001; Harachi et al. 2006; Lahey et al. 2006; Odgers et al. 2008; Schaeffer et al. 2006). Recently, as opposed to relying on teacher report only, studies have included multiple informants on the girls' disruptive behavior (Lahey et al. 2006; Odgers et al. 2008). Studies documented a mostly stable mean trajectory with a tendency towards a slight and gradual decrease of disruptive behaviors with increasing age. Furthermore, studies showed that a small group of girls, approximately $10 \%$ of the sample depending on the threshold or criteria determined by the investigator and the particular behavior of interest, displayed high levels of disruptive behavior early on. The largest group of girls, however, tended to show few disruptive behaviors in childhood.

\section{Rates of Disruptive Behavior in Adolescence}

With regard to psychiatric diagnostic classifications in adolescence, prevalence rates of CD in girls vary from 1.4 to $8 \%$ (see Maughan et al. 2004, for a review of recent studies). Prevalence rates of ODD in adolescent girls range from $1.0 \%$ to $3.5 \%$ (Breton et al. 1999; Lahey et al. 2000; Maughan et al. 2004; Romano et al. 2001; Simonoff et al. 1997). Prevalence rates of ODD, compared to those of CD, show less change and higher stability over time, with ODD remaining at similar levels from early childhood to middle adolescence (Maughan et al. 2004).

Regarding the developmental course of disruptive behavior in adolescence, studies show that girls, compared to boys, show a faster increase in disruptive behavior from early to late adolescence (Scaramella et al. 1999; Galambos et al. 2003). With regard to the developmental course of delinquent behavior, girls, in contrast to boys, tend to start showing delinquent behavior in adolescence (adolescence- onset), and relatively few exhibit a childhood-onset pattern (e.g. Côté et al. 2001; McCabe et al. 2004; Moffitt et al. 2001; Silverthorn et al. 2001). Although a number of hypotheses for female trajectories to (juvenile) delinquent behavior have been offered in recent years (e.g. Côté et al. 2001; Fergusson and Horwood 2002; Silverthorn and Frick 1999), there remains little agreement on the nature and timing of different problem behaviors as they unfold over time. Silverthorn and Frick (1999) concluded that the classic distinction between early- versus adolescent-onset is not applicable to girls since most girls show an adolescent-onset pattern. They hypothesized that the factors implicated in adolescent girls' antisocial behavior may exist in early and middle childhood but do not manifest themselves in problem behavior until adolescence. They therefore proposed a 'delayed-onset pathway'. More recently however, studies examining behavior trajectories have followed girls into adulthood (Odgers et al. 2008; Schaeffer et al. 2006) and showed that although the early onset group of girls is small in size, these girls appear to have more severe and pervasive problems and poorer outcomes pertaining to mental health, physical health and economic problems in adulthood. Evidence furthermore lends support to the notion that early onset of problem behaviors is a significant predictor of serious delinquency for a subgroup of girls (Côté et al. 2001; Harachi et al. 2006; Lanctôt and LeBlanc 2002), similar to males (for a review see Loeber and Farrington 2001).

\section{Girls' Desistance from Disruptive Behavior}

Little is known about girls' normative outgrowing of disruptive behavior during childhood and adolescence. Studies of boys show that desistance takes place throughout childhood and adolescence (Prinzie et al. 2005; Tremblay et al. 2004). The course and predictors of desistance from disruptive behavior in girls, however, are still very poorly documented (Giordano et al. 2002).

In summary, both approaches to assess behavioral deviancy (psychiatric assessments of CD and/or ODD and developmental trajectories of disruptive behavior) show rates of disruptive behavior in girls remaining low in early and middle childhood, but steadily increasing in the (mid)teens. Studies also show that a relatively small subgroup of girls shows disruptive behavior early on and that this group is at heightened risk for various suboptimal outcomes in adolescence and adulthood. Although researchers are not in agreement as to whether there are unique processes that explain conduct problems in girls compared to boys, there is some consensus that risk and protective factors exert their effects in different ways and magnitude for girls and boys (see e.g. Harachi et al. 2006; Moffitt et al. 2001; Storvoll and Wichstrom 2002). It is 
therefore necessary to develop a gender-specific model of the development of disruptive behavior, which takes into account the differential age of onset and phenotypic manifestations in girls.

\section{Family Functioning as an Explanatory Factor of Girls' Disruptive Behavior}

Several reviews (based mainly on male populations) have identified risk and protective factors associated with the development of disruptive and delinquent behavior within multiple domains of influence: the individual, family, school, peer group, and the community (Farrington 1987; Herrenkohl et al. 2001; Lipsey and Derzon 1998; Loeber and Dishion 1983; Yoshikawa 1994). Explanations for disruptive and delinquent behavior have included parental behavior (e.g. Gottfredson and Hirschi 1990; Patterson and Dishion 1985) for both boys and girls. Moreover, an extensive literature shows unique effects of parenting on girls' and boys' emotional and behavioral adjustment (e.g. Patterson et al. 1982; Patrick et al. 2005) and the ability of family focused interventions to change child behavior (see meta-analyses by Farrington and Welsh 2003, and Woolfenden et al. 2002).

Studies indicate that family processes may be particularly relevant for girls. For example, girls who display disruptive behavior, compared to boys, more often come from families characterized by dysfunction (e.g. Caspi and Moffitt 1991; Chamberlain and Reid 1994; Dakof 2000; Keenan et al. 2005; Lee et al. 1994), maltreatment (e.g. Giordano and Cernkovich 1997; Margolin and Gordis 2000), and higher levels of discord, deviance and conflict (Henggeler et al. 1987; Smith and Thomas 2000; Widom 1978). Two processes may be at work here. First, highly deviant girls may cause disruptions in the 'normative' child rearing environment. For example, Hipwell et al. (2008) reported that girls' conduct problems predicted increases in harsh punishment over a 6 year period (girls aged 7-12 years). This relationship was shown to be reciprocal such that this type of parenting behavior also predicted increases in girls' conduct problems over time. A prospective study by Huh et al. (2006) also revealed that adolescent girls' externalizing behavior and substance abuse predicted future decreases in the girls' perceptions of parental support and control. Studies on parental monitoring, mainly based on male samples however, furthermore showed that growth in conduct problems in both boys and girls reduced subsequent parental monitoring of children (Laird et al. 2003; Patrick et al. 2005; see also Stattin and Kerr 2000).

Second, suboptimal parenting behavior may cause girls to exhibit disruptive behavior. Some researchers have suggested that associations between parental behavior and child externalizing behavior were strongest when the measure of parenting tapped patterns of, as opposed to single, parent behaviors (e.g. Baumrind 1967, 1971; for a meta-analysis see Rothbaum and Weisz 1994). In an allfemale sample, for example, simultaneously low levels of parental warmth, supervision and monitoring (also referred to as a neglectful or disengaged parenting style) were detrimental to adolescents' functioning (e.g. Pittman and Chase-Lansdale 2001). Other scholars, however, have stressed the importance of simultaneously assessing and analyzing multiple parenting behaviors (Caron et al. 2006).

\section{Cross-sectional Studies}

Several cross-sectional studies examined the association between girls' disruptive behavior and parenting behaviors. In a sample of 64 girls and 158 boys (aged 4-7 years) diagnosed with oppositional defiant disorder (ODD) or early onset conduct problems, Webster-Stratton (1996) reported that two aspects of mother's observed parenting style ('critical statements', and 'total negativity' defined as physically negative behaviors and negative communication), as well as one type of observed paternal style ('communication', i.e. the number of non-intrusive descriptive statements) correlated with girls' externalizing behavior.

Research on adolescents also shows associations between parenting and girls' disruptive behavior. Jackson and Foshee (1998), for example, examined the association between adolescents' perceived parental responsiveness and physical fighting and weapon-carrying in a sample of 1,221 9th- and 10th-grade adolescents. Results indicated that the lower the perceived responsiveness of parents, the higher the likelihood that adolescents had hit their peers, fought with their peers, carried a weapon to school, or threatened a peer with a weapon. This bivariate association appeared for both boys and girls. Pittman and ChaseLansdale (2001), furthermore, examined the association between parenting style and adolescent functioning among 302 African American adolescent girls (aged 15-18 years) and their mothers living in impoverished neighborhoods. They found that teens whose mothers were disengaged (low on both parental warmth and supervision/monitoring) had the most negative outcomes related to externalizing behaviors, academic achievement, work orientation, sexual experience, and pregnancy history.

Besides examining parenting behaviors, studies on adolescents have also focused on the quality of the parentchild relationship. For example, mother-adolescent conflict was strongly positively related to adolescents' externalizing problems in a sample of 755 mother-adolescent (both boys and girls) dyads (Vandewater and Lansford 2005). Buehler (2006) reported concurrent and prospective 
associations between observed parent-youth dyadic hostility and externalizing problem behavior in 416 families with youth ranging in age from 11 to 14 years even when controlling for parents' inadequate control, parents' wellbeing, and adolescent affiliation with deviant friends. The pattern appeared similar for boys and girls. Furthermore, in a sample of 150 12- to 14- year-old Hispanic females drawn from a high-risk community, lower levels of support and higher levels of conflict in the family showed a strong association with girls' externalizing behavior problems (Coatsworth et al. 2000). Although conflict and support were modestly related to each other, they made independent contributions to the prediction of adolescents' reports of externalizing behavior.

In sum, data from cross-sectional studies suggests that disruptive behavior in girls, as in boys, is associated with low levels of parental warmth, support, supervision and monitoring and high levels of hostility and conflict. These associations appear in childhood and in adolescence and across different ethnic/racial groups. These results, however, cannot be unambiguously interpreted since all of the aforementioned studies used a cross-sectional design and temporal relationships cannot be determined. In addition, the design of these studies does not take into account the bidirectional association between parenting and the child's behavior nor changes in parenting behavior and child behavior over time. Only longitudinal, prospective studies are able to shed light on this dynamic, interactional process.

\section{Stability and Change in Parenting Behaviors}

Parenting behavior is known to vary with child age and should therefore be studied from a developmental point of view. Harsh parenting, such as hitting or spanking, for example, occurs more often during childhood than adolescence (Loeber et al. 2000; National Center on Child Abuse and Neglect 1996; Straus and Stewart 1999). At the same time, other studies have shown that parenting shows remarkable stability. Holden and Miller (1999) reviewed studies on the stability of parenting and found significant levels of relative stability (referring to the consistency of an individual's rank order within a group) on all constructs (such as control, monitoring, positive/negative affect etc.) with a median, moderate effect size of .38 .

Regarding absolute stability (referring to the consistency of the level of a particular behavior when measured over time), studies, mainly based on male samples, indicate that parental involvement, supervision, monitoring, warmth, physical punishment and the use of positive parenting techniques all decrease as the child grows older (Frick et al. 1999; Loeber et al. 2000).
Few studies, however, have examined the stability or the development of parenting behaviors in samples of girls or mixed samples of both boys and girls while conducting separate analyses on each gender. In a sample of 3rd grade children, Shumow et al. (1998) reported no gender differences in the relative stability of parenting behaviors over a 2-year-period. A similar finding was found in a mixedgender sample of 32 children (McNally et al. 1991). These studies, however, suffered from a short study time interval and a small sample, respectively. Forehand and Jones (2002) examined the stability of parental monitoring and warmth in a sample of 124 low-income, inner-city, African-American families with children who were on average eight years old at the beginning of the study. Test-retest correlation coefficients indicated that the relative stability of both parental monitoring and warmth over the four-year assessment period was high. In contrast, analyses of variance did not provide evidence for absolute stability as both parental monitoring and warmth declined across assessments for both boys and girls.

Studies of adolescents' perceptions of family functioning further add to our knowledge of the development of parenting over time. McGue et al. (2005), for example, showed that adolescents' perceptions of the quality of the parent-child relationship declined consistently and moderately between age 11 and age 14 (conflict with parents increased, whereas all aspects of warmth decreased) and that these perceived changes were significantly greater for girls than boys (McGue et al. 2005). Female adolescents (ages 10-19) from single-parent-families, furthermore, reported the highest levels of anger and conflict with the mother in early and middle adolescence while male adolescents reported the highest levels of conflict in middle adolescence (Dworkin and Larson 2001). It should be noted, however, that these studies used self report and therefore measured the adolescents' perception as opposed to the actual change in quality measured by observational methods. Observational studies, however, are rare in older children and adolescents.

In sum, although more is known about stability of parenting behavior in boys, high relative stability is also likely to exist in girls. Regarding absolute stability of parenting of girls, parental monitoring and warmth have been shown to decline over time. In addition, girls, compared to boys, report greater changes in the quality of the parent-child relationship in early adolescence (McGue et al. 2005).

\section{Longitudinal Studies on Family Functioning and Girls' Disruptive Behavior}

There have been few studies that prospectively examined the association between family functioning and girls' 
disruptive behavior. A study by McFadyen-Ketchum et al. (1996) reported that boys who had mothers who were observed to be highly controlling and low in affection showed an increase in physical and verbal aggressive behavior at school (as measured by Teacher Report Form) from kindergarten to third grade. Interestingly, girls of mothers showing similar behaviors (i.e. highly controlling and low in affection) showed a decrease in aggressiveness over these four years. Two important issues should be noted, however. First, only verbal and physical aggression were measured, while relational aggression, was not. Second, since aggression is known to decrease over middle childhood and this decrease is known to start earlier in girls than boys, the results could also represent the 'normative' developmental pattern of girls' physical aggression. A more recent study of the same sample that used nine waves of data collection (Pettit et al. 2001), showed that parental monitoring was associated with fewer delinquent behavior problems for both boys and girls across time. On the other hand, high levels of psychological control (e.g. love withdrawal, guilt induction) were associated with more delinquent behavior problems for girls. In another study, Kilgore et al. (2000) investigated the association of parental discipline and monitoring with the early conduct problems of 123 boys and girls in a highly disadvantaged, African American sample. Prospective analyses indicated that, after controlling for earlier conduct problems, coercive parent discipline and poor parental monitoring at age $4 \frac{1}{2}$ years were independent predictors of conduct problems at age 6 for both boys and girls.

Instead of focusing on the negative effects of parenting behaviors, some longitudinal studies examined protective processes. Scaramella et al. (1999), for example, examined parental protective influences on adolescent externalizing problems in a sample of seventh-graders (average 12 years of age, followed up over a five-year-period) drawn from the general population in a rural, mainly white area. The authors reported that adolescents with parents above the median in warmth, child management skills (consistent discipline and monitoring) and low hostility showed fewer externalizing problems and had lower growth trajectories than their counterparts. Chronis et al. (2007) conducted seven diagnostic assessments over eight years and examined parenting factors in 108 children who first met diagnostic criteria for Attention Deficit Hyperactivity Disorder (ADHD) at age 4-7 years old (approximately one-fifth were girls). After controlling for demographic variables, baseline ADHD and conduct problems, observed positive parenting (including praise, positive affect, physical warmth) predicted fewer conduct problems 2-8 years following the initial assessment. Surprisingly, observed negative parenting did not predict the future course of conduct problems. This may have been because mothers were less likely to exhibit negative parenting during the observed parent-child interaction due to social desirability. The authors suggested that this lack of variability likely minimized their ability to detect effects.

With the exception of the studies by Scaramella et al. (1999) and, previously mentioned, Hipwell et al. (2008) the majority of longitudinal studies assessed parenting behavior once and were therefore not able to study the development of parenting behaviors over time. Although the study by Scaramella et al. (1999) observed parenting twice, the two measurements were only one year apart and summed into a single composite measure. The authors reported moderate correlation coefficients between the two measurements, i.e. seventh and eighth grade parenting, ranging from .40 (maternal hostility) to .45 (paternal warmth) but did not comment on (the direction of) the observed changes, nor were separate analyses conducted for each gender. The study by Hipwell et al. (2008) took into account changes in parenting over time, but did not report on the nature of those changes. Another exception of studies with multiple measurements of parenting behavior pertains to the research focusing on parental monitoring, which shows both continuity and transformation of parental monitoring. Pettit et al. (2001) showed that monitoring at ages 13 and 14 appeared to be preceded by a proactive parenting style at age 5 , whereas psychological control was preceded by earlier harsh parenting. Mother's report of psychological control was preceded by earlier maternal judgments of child externalizing behavior problems at age 5. A study by Patrick et al. (2005), however, suggested that monitoring in later childhood (third and fourth grade) was only indirectly associated with earlier parenting skills at the entry of elementary school by their association with child conduct problems (reciprocal effect). None of these studies, however, examined the development of monitoring in girls or studied gender differences in the development of monitoring.

In summary, few longitudinal studies on girls have measured both child and parental behavior repeatedly. It is therefore difficult to draw conclusions about the dynamic, bidirectional association between girls' disruptive behavior and family functioning. Data from cross-sectional studies suggests that disruptive behavior in girls, as in boys, is associated with low levels of parental warmth, support, supervision and monitoring and high levels of hostility and conflict. Conclusions from the longitudinal studies, however, are less conclusive. Although studies show an association between girls' disruptive behavior and parental monitoring, psychological control and coercive parental discipline (Kilgore et al. 2000; Pettit et al. 2001), other studies do not report associations between suboptimal parenting behaviors and the development of disruptive behavior in girls over time (Chronis et al. 2007; McFadyen- 
Ketchum et al. 1996). Due to the scarcity of longitudinal studies with repeated measurements of parental and girls' behavior, we do not know how the parental behaviors associated with disruptive behavior, develop over time as they influence and are influenced by the girl's disruptive behavior. Furthermore, we are not aware of any study that examined the longitudinal development of parent-daughter conflict.

To What Extent Can Risk and Protective Factors Related to Family Functioning Explain the Differential Development of Disruptive Behavior in Girls?

Several scholars have reviewed parental socialization as a potential explanation for a lower overall prevalence of disruptive behavior in girls, compared to boys (Crick and Zahn-Waxler 2003; Keenan and Shaw 1997; Maniadaki et al. 2003; Zahn-Waxler and Polanichka 2004). These reviews show that parents interact differently with girls and boys (Crick and Zahn-Waxler 2003; Keenan and Shaw 1997; Lytton and Romney 1991; Zahn-Waxler and Polanichka 2004). Differences include a parental focus on interpersonal relationships in girls by emphasizing the need for prosocial behaviors such as considering the personal consequences of their actions, and the need to control/mask their feelings of anger and aggression. Girls, in contrast to boys, also tend to be treated by their parents with less aggression and physical punishment, and with more warmth (Lytton and Romney 1991; Zahn-Waxler and Polanichka 2004). Regarding parenting behaviors, studies examining adolescents' development of substance use and affiliation with deviant peers consistently report that girls, compared to boys, are more closely monitored by parents (e.g. Kim et al. 1999; Svensson 2003; Wall and Barth 2005; Webb et al. 2002). The typical parental socialization of girls may function as a protective factor against the development of disruptive behavior in childhood and therefore may explain why the majority of girls do not show disruptive behavior in childhood or adolescence. Girls' typical socialization focussing on interpersonal relationships and suppression of anger and curtailing aggression may, for example, explain why girls show less physical aggression than boys, and use relational aggression instead. In addition, higher levels of parental supervision and monitoring tend to be associated with higher rates of secure attachment relationships between parent and child. Securely attached children internalize the values of their parents and in turn are less likely to become affiliated with deviant peers (Giordano et al. 1986). Due to the fact that girls, compared to boys, show lower levels of problem behavior in childhood and the majority of girls do relatively well in elementary school, parents are likely to refrain from changing their parenting behaviors which may explain the relatively stable levels of parenting behavior found in middle childhood (Forehand and Jones 2002). These high levels of stability in turn, may further increase the protective effect of parenting.

Evidence pointing in the same direction comes from studies indicating that normative gender-differentiated parenting styles become disrupted in the face of children with conduct problems. Two studies of high-risk samples of 15- to 18-year-old adolescents, for example, showed a similar distribution of the four parenting styles (authoritative, authoritarian, permissive/indulgent, and neglectful/ disengaged parenting) across boys and girls (Pittman and Chase-Lansdale 2001; Steinberg et al. 2006). In addition, no differences in parent reported parenting practices by gender were found in a clinical sample of 4- to 7-year-olds diagnosed with ODD or early onset conduct problems (Webster-Stratton 1996).

As discussed previously, a relatively small subgroup of girls shows high levels of disruptive behavior in childhood (Côté et al. 2001; Hipwell et al. 2002, Lanctôt and LeBlanc 2002; McCabe et al. 2004; Odgers et al. 2008). These girls are often characterized by highly dysfunctional families in terms of suboptimal parenting and levels of conflict. These girls may have developed disruptive behavior in the absence of the protective effect of parenting. It may, however, also be the case that the highly deviant behavior of the girl causes disruptions in the child-rearing environment, which in turn, is likely to further increase or escalate the girl's disruptive behavior. Studies on the reciprocal association between child disruptive behavior and parental behavior provide support for this hypothesis (Hipwell et al. 2008; Huh et al. 2006). In addition, girls who display aggressive, antisocial tendencies are more likely, due to the existing gender stereotype, to be rejected by their parents, teachers and peers. This, in turn, further increases the risk of developing disruptive behavior and may potentially explain the small subgroup of girls that shows disruptive behavior from early childhood onwards.

A third, relatively large, subgroup of girls exhibits adolescent-onset of disruptive behavior (e.g. Côté et al. 2001; Galambos et al. 2003; Moffitt et al. 2001; Scaramella et al. 1999; Silverthorn et al. 2001), suggesting that the peri- and post-pubertal period is one of particular risk for conduct problems in girls. The transition from childhood into adolescence appears to be a time of transformation in parent-adolescent relationships. Parental monitoring, for instance, decreases whilst parent-daughter conflict increases (e.g. Dworkin and Larson 2001; Forehand and Jones 2002; Holmbeck and Hill 1991; Sagrestano et al. 1999). During this time, conflicts between parents and their children potentially serve an adaptive function by signaling to parents and youth that relationship structures and processes require attention and redefinition (Holmbeck and Hill 
1991). The transition from childhood into adolescence is also marked by an increase in time spent with peers outside the home, therefore increasing the influence of peers and potentially reducing the protective effects of positive parenting behaviors. Among boys, it is well established that involvement with deviant peers is associated with conduct disorder and delinquency (e.g. Elliott et al. 1985; Patterson and Dishion 1985). Less is known about girls, although such an association appears to exist for antisocial females (Aseltine 1995). It has also been argued that peer influence might be more important for girls than for boys, because girls' friendships are characterized by greater intimacy, loyalty and interpersonal engagement (Buhrmester and Furman 1987; Savin-Williams and Berndt 1990; see review by Rose and Rudolph 2006). Girls typically enter mixedage and mixed-sex peer groups earlier than boys (Vitaro et al. 2001), which may get them in contact with older, deviant males. Antisocial females tend to affiliate with older, antisocial males, which may increase the risks for relationship difficulties, teenage pregnancies and antisocial behaviors (Moffitt 1993).

The different subgroups of girls (no disruptive behavior, childhood-onset disruptive behavior and adolescence-onset disruptive behavior) may be distinguishable early in life, for example by temperamental factors such as negative emotionality or impulsivity. Côté et al. (2002) showed that girls who were both hyperactive and unhelpful in childhood had a significant risk for CD in adolescence. McCabe et al. (2004) showed that girls with childhood-onset disruptive behavior were more likely to have a family history of mental illness or a family history of antisocial behavior than girls with adolescent-onset. This finding points towards familial influence, but may also be indicative of biological causes of the development of psychopathology (Moffitt 2005). Girls exhibiting an early onset of disruptive behavior also differed from adolescent-onset girls on below median household income and comorbid ADHD (McCabe et al. 2004). In addition, Odgers et al. (2008) reported that the life-course persistent path, as opposed to the adolescence-limited subtype, in females was differentially predicted by low intellectual ability, reading difficulties, hyperactivity, maternal poor mental health, experiences of harsh and inconsistent discipline, much family conflict and low family socio-economic status. Previous studies suggest that childhood-onset girls can be differentiated from adolescence-onset girls (see also Moffitt and Caspi 2001).

The role of family functioning in desistance processes in girls has yet to be studied fully. However, Formoso et al. (2000) suggested that continuous parental involvement and support despite the girl's behavior problems in adolescence may protect the girl from persistent disruptive and delinquent behavior in late adolescence and adulthood. They showed that girls in conflictual families who reported stronger bonds with their mothers and closer supervision by their parents exhibited lower levels of conduct problems than girls without such strong bonds or close supervision. In addition to this indirect effect, studies also showed a direct protective effect of parenting on the development of disruptive behavior (Chronis et al. 2007; Scaramella et al. 1999). Scaramella and colleagues showed that observed parenting that is high in warmth, low in hostility and highly consistent in management behaviors inhibits growth of externalizing behavior in adolescents through a compensatory main effect (exhibiting lower levels of initial externalizing behavior) and through a buffering effect that reduced increases in these problem behaviors over time.

\section{A Gender Specific Family Model of Girls' Disruptive Behavior}

The preceding text makes it clear that many factors are important in the development of girls' disruptive behavior. So far very few models that specify the relationship between the different factors are available in the literature. Based on the findings from this review, we have formulated a normative social model of the development of disruptive behavior in girls (depicted in Fig. 1).

Girls, as a result of typical socialization practices and other potential factors (such as temperamental, genetic and hormonal factors), show a greater orientation to interpersonal relations and higher sensitivity to rejection than boys. This orientation and sensitivity towards interpersonal relationships, in turn, is likely to cause girls to be particularly affected by disruptions in their childrearing environment (such as high levels of familial conflict and suboptimal parenting) and problematic relationships with peers (such as rejection by peers and affiliation with deviant peers).

These familial and peer related risk factors are both directly as well as indirectly related to disruptive behavior. Suboptimal parenting, for example, is associated with affiliation with deviant peers (Brody et al. 2001; Kim et al. 1999; Simons et al. 1996; Svensson 2003). Several mechanisms may be at work here. First, children who do not receive emotional support from their parents lack a primary source of socialization in conventional values, and will be less accepting of those values and more disposed to associate with deviant peers (Jessor and Jessor 1977). Second, children who receive harsh parenting are likely to learn aversive tactics to resolve interpersonal conflicts and may not have acquired the prosocial skills required for maintaining supportive peer relationships (Snyder and Patterson 1995). These children are more likely to be rejected by conventional peers and to affiliate with peers similar to themselves (Simons et al. 1991). 
Fig. 1 A normative social model of the development of disruptive behavior in girls

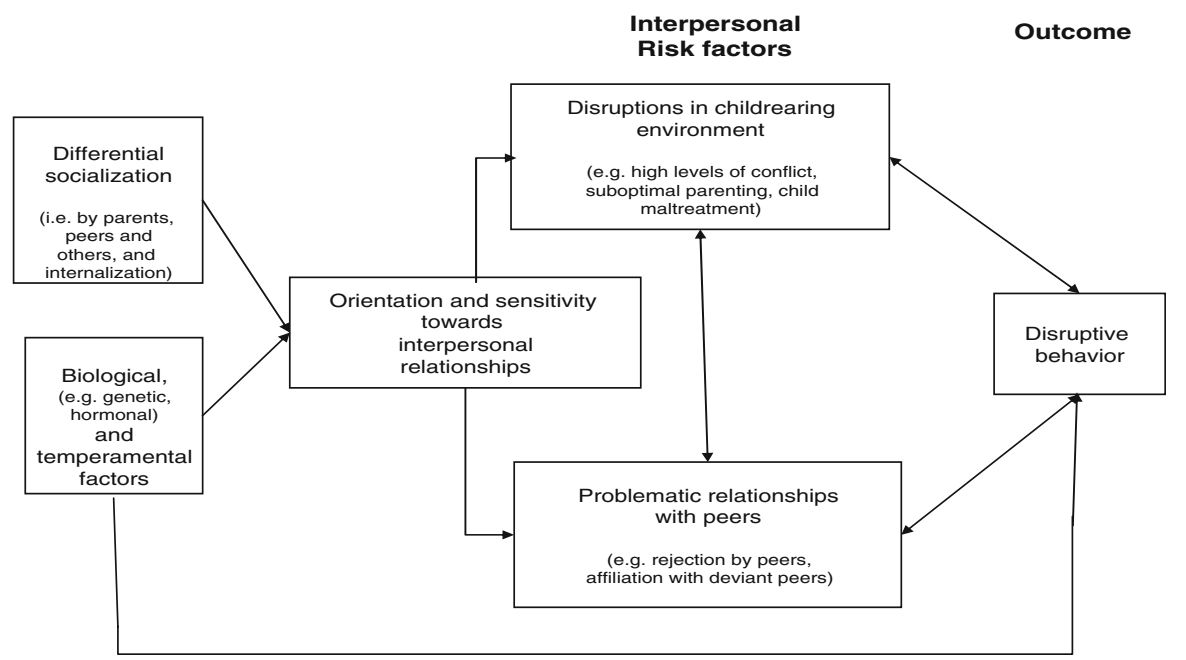

Affiliation with deviant peers, may also reduce a girl's willingness to share information about her whereabouts, making it more challenging for the parent to monitor her (Stattin and Kerr 2000). Lower levels of parental monitoring, in turn, may cause an increase in disruptive behavior. Besides that, girls' affiliation with deviant peers may cause parental distress (as the parents may fear future police arrests, pregnancy etc.), which in turn may increase parent-daughter conflict and undermine effective parenting.

As shown in the model by two-sided arrows bidirectional or reciprocal effects exist between disruptive behavior and both disruptions in childrearing environment and problematic relationships with peers. Increases in girls' disruptive behavior are associated with (increased) affiliation with deviant peers (since girls who display aggressive, antisocial tendencies are likely to be rejected by parents, teachers and conventional peers due to the existing gender stereotype) and predict (further) deteriorations in the parent-child relationship and child-rearing practices (Huh et al. 2006; Laird et al. 2003; Patrick et al. 2005; Stattin and Kerr 2000).

Studies on boys show that no single risk factor but rather an accumulation of multiple risk factors (in different domains) is associated with the development of delinquent behavior (e.g. Stouthamer-Loeber et al. 2002; Yoshikawa 1994). We are not aware, however, of any studies examining the accumulation of familial and peer risk factors in girls. As a result, we do not know whether these effects are additive, multiplicative or whether they are different manifestations of the same underlying factor. Furthermore, the accumulation of risk factors may also be buffered by protective factors, such as academic achievement or (above) average intellectual functioning.

The gender-specific model of the developmental course of disruptive behavior in girls shown in Fig. 1 can only be tested in large longitudinal samples that follow parents and children from early development through late adolescence. Such studies should be able to simultaneously test familial and peer factors as well as examine protective factors that reduce the likelihood of conduct problems in the context of risk factors. These studies are crucial for enhancing our understanding of familial factors in the onset, development and desistance of disruptive behaviors among girls.

\section{Conclusions}

The current review focused on family linked risk and protective processes in girls' disruptive behavior and aimed to fill a gap in knowledge about the differential development of disruptive behaviors among girls. However, before turning to the conclusions, several limitations of the current review should be noted. First, we did not aim to give an extensive overview of all risk factors of girls' development of disruptive behavior. Instead, we focused primarily on family processes. Second, we referred to studies of boys as a source of comparison or because studies of girls were lacking, but we did not aim to explain gender differences in the association between parental behavior and the child's disruptive behavior. Third, we mainly focused on middle childhood and adolescence since this is the time when an increase in disruptive behavior appears in girls. Fourth, aside from the gender and behavior of the child, parenting behavior is also influenced by multiple other factors such as genetic make-up, socioeconomic status, race/ethnicity, parental mental health and neighborhood of residence. The current paper did not address these factors since the focus was on girls and studies examining the association between these factors and parenting practices in girls are rare or nonexistent. Finally, although a meta-analysis would have been of great value, such an approach was beyond the scope of the present review. This is however, an important gap that needs to be addressed in the future. 
Despite these limitations, the current review shows the importance of including family functioning when studying the etiology and developmental course of girls' disruptive behavior. To summarize key aspects of the current review, studies have shown that the majority of girls do not develop disruptive or delinquent behavior in childhood or adolescence. A small subgroup does, however, show disruptive behavior from an early age. Early onset of disruptive behavior is associated with negative outcomes in adulthood including antisocial behavior, unemployment, substance use, mental health and parenting problems. A larger subgroup starts showing disruptive behavior in early adolescence. Although studies suggest that girls displaying childhood-onset disruptive behavior can be differentiated from those with an onset in adolescence, it is still unclear how these differential processes in girls can be explained. As summarized previously, there is some evidence from prospective studies that a suboptimal child-rearing environment (low levels of parental monitoring, and high levels of psychological control, coercive parental discipline and conflict) is linked to early onset disruptive behavior in girls. Relationships with peers may also be key, as research extensively documented girls' greater orientation and sensitivity towards interpersonal relationships and some study findings suggested that rejection by (conventional) peers and affiliation with deviant peers is associated with problem behaviors at an early age (e.g. Hipwell et al. 2005; Snyder et al. 2005). In adolescence, there is some evidence for a connection between decreasing levels of parental monitoring and warmth and increasing levels of parentadolescent conflict, and emergence of disruptive behavior, at least for a subgroup of girls. To date, however, trajectories of disruptive behavior have not yet been combined with trajectories of parenting behavior. Although a high relative stability of parenting behavior is likely to exist, studies on monitoring for example show both continuity and change over time (i.e., low absolute stability). It is therefore crucial to examine to what extent and in what way the changes over time in parenting behavior affect, or are influenced by the child's behavior, during the preadolescent period. It is also crucial to study desistance from disruptive behavior in girls, because this will enhance our understanding of developmental processes associated with girls' disruptive behavior.

Early adolescence thus appears to be a crucial period for the development of disruptive behavior in girls. Besides being a time of transformation in parent-adolescent relationships, it also marks a transition from family to peer orientation, with decreasing parental influence and increasing association with, and influence of (deviant, older male) peers. Relationships with peers may be particularly relevant for girls, as they are typically more oriented to interpersonal relations and more sensitive to rejection than boys, and because girls' relationships with their peers are characterized by greater intimacy, loyalty and interpersonal engagement.

In addition to changes in environmental factors, girls also experience biological changes (e.g. hormonal processes, brain development, gains in physical size and strength) during this time. Further research is needed to examine the effect of biological changes on the girls' behavioral and emotional development and the ways in which they interact with family factors. Recently, studies have examined girls' behavior trajectories into adolescence and adulthood (Odgers et al. 2008; Schaeffer et al. 2006). These studies may shed light on behavioral changes resulting from important developmental shifts in biological and contextual factors during the transitions into and out of adolescence. More research is also needed to examine the extent to which these processes differ among different ethnic groups (for a review on parenting in African American, Latino and Asian American families see McLoyd et al. 2000). Furthermore, future studies should also take neighborhood factors into account since residence in dangerous or impoverished neighborhoods is associated with more restrictive parenting practices (e.g. Furstenberg 1993). Several investigators, mainly reporting on male samples, have suggested that the beneficial effects of parental monitoring, for example, may be more evident for children living in the most disadvantaged neighborhoods (Loeber and Stouthamer-Loeber 1986; Wikström and Loeber 2000; Simons et al. 2002). Finally, socioeconomic status is also hypothesized to further explain differences in girls' developmental trajectories since chronically poor families have been shown to provide lower quality childrearing environments than more advantaged families due to pervasive and chronic stressors associated with poverty (Dearing et al. 2005).

\section{Clinical Implications}

The findings of the current review indicate that prevention and intervention programs should ideally start or intensify just before the girl's transition from childhood to adolescence. Since family functioning is clearly important in the development of disruptive behavior in girls, and findings suggest that this relationship is reciprocal, it is crucial for intervention programs to include parents in parent training programs or systemic therapies. Treatment programs, furthermore, should be specifically designed for girls and target girl specific problem behaviors such as relational aggression. The review suggests that a greater emphasis on building more positive relationships with parents (and peers) may be a critical component of effective, multicomponent interventions for girls. Since multiple factors are associated with the development of girls' disruptive 
behavior, the treatment of just one component (e.g. parent management skills) is likely to be insufficient to overcome other problems (e.g., social dysfunction in contact with peers) (Hipwell and Loeber 2006).

We know that childhood disruptive behavior is associated with negative outcomes in adulthood including delinquency, substance use, mental health, physical health and parenting problems (Bardone et al. 1996; Chamberlain and Moore 2002; Lewis et al. 1991; Odgers et al. 2008; Serbin et al. 1991). It is therefore critical to provide interventions that prevent girls from following a pathway to suboptimal outcomes. Studying the development of disruptive behavior in girls by adopting a developmental perspective that depicts dynamic relations between parent and child behavior, is an important step in the development of such interventions. Attention, however, should also be paid to protective processes associated with family functioning since knowledge of nondeviance and desistance processes will further enhance our understanding of girls' disruptive behavior and contribute to designing effective interventions for girls.

Open Access This article is distributed under the terms of the Creative Commons Attribution Noncommercial License which permits any noncommercial use, distribution, and reproduction in any medium, provided the original author(s) and source are credited.

\section{References}

Alink, L. R. A., Mesman, J., van Zeijl, J., Stolk, M. N., Juffer, F., Koot, H. M., et al. (2006). The early aggression curve: Development of physical aggression in 10- to 50- month-old children. Child Development, 77, 954-966.

American Psychiatric Association. (1994). Diagnostic and statistical manual of mental disorders, (DSM-IV) (4th ed.). Washington, DC: American Psychiatric Association.

Aseltine, R. H. (1995). A reconsideration of parental and peer influences on adolescent deviance. Journal of Health and Social Behavior, 36, 103-121.

Bardone, A. M., Moffitt, T., Caspi, A., \& Dickson, N. (1996). Adult mental health and social outcomes of adolescent girls with depression and conduct disorder. Development and Psychopathology, 8, 811-829.

Baumrind, D. (1967). Child care practices anteceding three patterns of preschool behavior. Genetic Psychology Monographs, 75, 43-88.

Baumrind, D. (1971). Current patterns of parental authority. Developmental Psychology, 4, 1-103.

Bjorkqvist, K., Lagerspetz, K., \& Kaukianen, A. (1992). Do girls manipulate and boys fight? Developmental trends in regard to direct and indirect aggression. Aggressive Behavior, 18, 117-127.

Bongers, I. L., Koot, J. M., van der Ende, J., \& Verhulst, F. C. (2004). Developmental trajectories of externalizing behaviors in childhood and adolescence. Child Development, 75, 1523-1537.

Breton, J. J., Bergeron, L., Valla, J. P., Berthiaume, C., \& Gaudet, N. (1999). Quebec child mental health survey: Prevalence of DSMIII-R mental health disorders. Journal of Child Psychology and Psychiatry, 40, 375-384.

Brody, G. H., Ge, X., Conger, R., Gibbons F. X., Murry V. M., Gerrard M., et al. (2001). The influence of neighborhood disadvantage, collective socialization, and parenting on African American children's affiliation with deviant peers. Child Development, 72, 1231-1246.

Broidy, L. M., Nagin, D. S., Tremblay, R. E., Bates, J. E., Brame, B., Dodge, K. A., et al. (2003). Developmental Psychology, 39, 222245.

Buehler, C. (2006). Parents and peers in relation to early adolescent problem behavior. Journal of Marriage and Family, 68, 109124.

Buhrmester, E., \& Furman, W. (1987). The development of companionship and intimacy. Child Development, 58, 1101-1113.

Campbell, S. B. (1995). Behavior problems in preschool children: A review of recent research. Journal of Child Psychology and Psychiatry and Allied Disciplines, 36, 113-150.

Caron, A., Weiss, B., Harris, V., \& Catron, T. (2006). Parenting behavior dimensions and child psychopathology: Specificity, task dependency, and interactive relations. Journal of Clinical Child and Adolescent Psychology, 35, 34-45.

Caspi, A., \& Moffitt, T. E. (1991). Individual differences are accentuated during periods of social change: The sample case of girls at puberty. Journal of Personality and Social Psychology, 61, 157-168.

Chamberlain, P., \& Moore, K. J. (2002). Chaos and trauma in the lives of adolescent females with antisocial behavior and delinquency. In R. Greenwald (Ed.), Trauma and juvenile delinquency: Theory and interventions (pp. 79-108). Binghamton, NY: Haworth Maltreatment and Trauma Press.

Chamberlain, P., \& Reid, J. B. (1994). Differences in risk factors and adjustment for male and female delinquents in Treatment Foster Care. Journal of Child and Family Studies, 3, 23-39.

Chronis, A. M., Lahey, B. B., Pelham, W. E., Williams, S. H., Baumann, B. L., Kipp, H., et al. (2007). Maternal depression and early positive parenting predict future conduct problems in young children with attention-deficit/hyperactivity disorder. Developmental Psychology, 43, 70-82.

Cicchetti, D. (1993). Developmental psychopathology: Reactions, reflections, projections. Developmental Review (Special issue: Setting a path for the coming decade: Some goals and challenges) , 13, 471-502.

Coatsworth, J. D., Pantin, H., McBride, C., Briones, E., Kurtines, W., \& Szapocznik, J. (2000). Ecodevelopmental correlates of behavior problems in young Hispanic females. Applied Developmental Science, 6, 126-143.

Costello, E. J., Angold, A., Burns, B., Stangl, D., Tweed, D., Erkanli, A., et al. (1996). The great smokey mountains study of youth: Goals, design, methods, and the prevalence of DSM-III-R disorders. Archives of General Psychiatry, 53, 1129-1136.

Costello, E. J., Armstrong, T. D., \& Erkanli, A. (2000). Report on the developmental epidemiology of comorbid psychiatric substance use disorders. Washington, DC: National Institute on Drug Abuse.

Costello, E. J., Foley, D. L., \& Angold, A. (2006). 10-year research update review: The epidemiology of child and adolescent psychiatric disorders: II. Developmental epidemiology. Journal of the American Academy of Child and Adolescent Psychiatry, $45,8-25$.

Côté, S., Tremblay, R. E., Nagin, D., Zoccolillo, M., \& Vitaro, F. (2002). The development of impulsivity, fearfulness and helpfulness during childhood: Patterns of consistency and change in the trajectories of boys and girls. Journal of Child Psychology and Psychiatry, 43, 609-618.

Côté, S., Zoccolillo, M., Tremblay, R. E., Nagin, D., \& Vitaro, F. (2001). Predicting girls' conduct disorder in adolescence from childhood trajectories of disruptive behaviors. Journal of the American Academy of Child and Adolescent Psychiatry, 40, 678-684. 
Crick, N. R., \& Grotpeter, J. R. (1995). Relational aggression, gender, and social-psychological adjustment. Child Development, 66, 710-722.

Crick, N. R., Ostrov, J. M., \& Werner, N. E. (2006). A longitudinal study of relational aggression, physical aggression and children's social-psychological adjustment. Journal of Abnormal Child Psychology, 34, 131-142.

Crick, N. R., Werner, N. E., Casas, J. F., O’Brien, K. M., Nelson, D. A., Grotpeter, J. K., et al. (1999). Childhood aggression and gender: A new look at an old problem. In D. Bernstein (Ed.), Gender and motivation. Nebraska symposium on motivation (Vol. 45, pp. 75-141). Lincoln, NE, US: University of Nebraska Press.

Crick, N. R., \& Zahn-Waxler, C. (2003). The development of psychopathology in females and males: Current progress and future challenges. Development and Psychopathology, 15, 719742 .

Dakof, G. A. (2000). Understanding gender differences in adolescent drug abuse: Issues of comorbidity and family functioning. Journal of Psychoactive Drugs, 32, 25-32.

Dearing, E., McCartney, K., \& Taylor, B. A. (2005). Change in family income-to-needs matters more for children with less. In Child care and child development: Results from the NICHD study of early child care and youth development (pp. 140-150). New York, NY, US: Guilford Press.

Dworkin, J. B., \& Larson, R. (2001). Age trends in the experience of family discord in single-mother families across adolescence. Journal of Adolescence, 24, 529-534.

Elliott, D. S., Huizinga, D., \& Ageton, S. S. (1985). Explaining delinquency and drug use. Thousand Oaks, CA: Sage Publications.

Esbensen, F., Deschenes, E., \& Winfree, L. T. (1999). Differences between gang girls and gang boys: Results from a multisite survey. Youth and Society, 31, 27-53.

Farrington, D. P. (1987). Early precursors of frequent offenders. In J. Q. Wilson \& G. C. Loury (Eds.), From children to citizens: Families, schools, and delinquency prevention (pp. 27-50). New York: Springer-Verlag.

Farrington, D. P., \& Welsh, B. C. (2003). Family-based prevention of offending: A meta-analysis. Australian and New Zealand Journal of Criminology, 36, 127-151. http://elwood.psy.vu.nl/ AAP/loi/acri.

Fergusson, D. M., \& Horwood, L. J. (2002). Male and female offending trajectories. Development and Psychopathology, 14, 159-177.

Forehand, R., \& Jones, D. J. (2002). The stability of parenting: A longitudinal analysis of inner-city African-American mothers. Journal of Child and Family Studies, 11, 455-467.

Formoso, D., Gonzales, N. A., \& Aiken, L. S. (2000). Family conflict and children's internalizing and externalizing behavior: Protective factors. American Journal of Community Psychology, 28, 175-199.

Frick, P. J., Christian, R. E., \& Wootton, J. M. (1999). Age trends in the association between parenting practices and conduct problems. Behavior Modification, 23, 106-128.

Furstenberg, F. F. (1993). How families manage risk and opportunity in dangerous neighbourhoods. Sociology and the public agenda (pp. 231-258). Newbury Park, California: Sage Publications.

Gabriel, S., \& Gardner, W. L. (1999). Are there "his" and "hers" types of interdependence? The implications of gender differences in collective versus relational interdependence for affect, behavior, and cognition. Journal of Personality and Social Psychology, 77, 642-655.

Galambos, N. L., Barker, E. T., \& Almeida, D. M. (2003). Parents do matter: Trajectories of change in externalizing and internalizing problems in early adolescence. Child Development, 74, 578-594.
Galen, B. R., \& Underwood, M. K. (1997). A developmental investigation of social aggression among children. Developmental Psychology, 33, 589-600.

Giordano, P. C., \& Cernkovich, S. A. (1997). Gender and antisocial behaviour. In D. M. Stoff, J. Breiling, \& J. D. Maser (Eds.), Handbook of antisocial behavior (pp. 496-510). New York: Wiley.

Giordano, P. C., Cernkovich, S. A., \& Pugh, M. D. (1986). Friendships and delinquency. American Journal of Sociology, 91, 1170-1202.

Giordano, P. C., Cernkovich, S. A., \& Rudolph, J. L. (2002). Gender, crime and desistance: Toward a theory a cognitive transformation. American Journal of Sociology, 107, 990-1064.

Gottfredson, M. R., \& Hirschi, T. (1990). A general theory of crime. Stanford, CA: Stanford University Press.

Harachi, T. W., Fleming, C. B., White, H. R., Ensminger, M. E., Abbott, R. D., Catalano, R. F., et al. (2006). Aggressive behavior among girls and boys during middle childhood: Predictors and sequelae of trajectory group membership. Aggressive Behavior, 32, 279-293.

Heide, K. M. (2003). Youth homicide: A review of the literature and a blueprint for action. International Journal of Offender Therapy and Comparative Criminology, 47, 6-36.

Henggeler, S., Edwards, J., \& Borduin, C. (1987). The family relations of female juvenile delinquents. Journal of Abnormal Child Psychology, 15, 199-209.

Herrenkohl, T., Hawkins, D., Chung, I., Hill, K., \& Battin-Pearson, S. (2001). School and community risk factors and interventions. In R. Loeber \& D. P. Farrington (Eds.), Child delinquents: Development, intervention and service needs. Thousand Oaks, CA: Sage.

Hipwell, A. E., Keenan, K., Kasza, K., Loeber, R., StouthamerLoeber, M., \& Bean, T. (2008). Reciprocal influences between girls' behavioral and emotional problems and parental punishment and warmth: A six year prospective analysis. Journal of Abnormal Child Psychology, 36, 663-677.

Hipwell, A. E., \& Loeber, R. (2006). Do we know which interventions are effective for disruptive and delinquent girls? Clinical Child and Family Psychology Review, 9, 221-255.

Hipwell, A. E., Loeber, R., Stouthamer-Loeber, M., Keenan, K., White, H. R., \& Kroneman, L. (2002). Characteristics of girls with early onset disruptive and antisocial behaviour. Criminal Behaviour and Mental Health, 12, 99-118.

Hipwell, A. E., White, H. R., Loeber, R., Stouthamer-Loeber, M., Chung, T., \& Sembower, M. A. (2005). Young girls' expectancies about the effects of alcohol, future intentions and patterns of use. Journal of Studies on Alcohol, 66, 630-639.

Holden, G. W., \& Miller, P. C. (1999). Enduring and different: A meta-analysis of the similarities in parents' child rearing. Psychological Bulletin, 125, 223-254.

Holmbeck, G. N., \& Hill, J. P. (1991). Conflictive engagement, positive affect, and menarche in families with seventh-grade girls. Child Development, 62, 1030-1048.

Huh, D., Tristan, J., Wade, E., \& Stice, E. (2006). Does problem behavior elicit poor parenting? A prospective study of adolescent girls. Journal of Adolescent Research, 21, 185-204.

Jackson, C., \& Foshee, V. A. (1998). Violence-related behaviors of adolescents: Relations with responsive and demanding parenting. Journal of Adolescent Research, 13, 343-359.

Jessor, R., \& Jessor, S. L. (1977). Problem behavior and psychosocial development: A longitudinal study of youth. New York: Academic Press.

Keenan, K., \& Shaw, D. (1997). Developmental and social influences on young girls' early problem behavior. Psychological Bulletin, 121, 95-113.

Keenan, K., Stouthamer-Loeber, M., \& Loeber, R. (2005). Developmental approaches to studying conduct problems in girls. In D. J. 
Pepler, K. C. Madsen, C. Webster, \& K. S. Levene (Eds.), The development and treatment of girlhood aggression (pp. 29-46). Mahwah, NJ: Lawrence Erlbaum Associates.

Keiley, M. K., Bates, J. E., Dodge, K. A., \& Pettit, G. S. (2000). A cross-domain growth analysis: Externalizing and internalizing behaviors during 8 years of childhood. Journal of Abnormal Child Psychology, 28, 161-179.

Kilgore, K., Snyder, J., \& Lentz, C. (2000). The contribution of parental discipline, parental monitoring, and school risk to earlyonset conduct problems in African American boys and girls. Developmental Psychology, 36, 835-845.

Kim, J. E., Hetherington, E. M., \& Reiss, D. (1999). Associations among family relationships, antisocial peers, and adolescents' externalizing behaviors: Gender and family type differences. Child Development, 70, 1209-1230.

Kloosterman, M., \& Veerman, J. W. (1997). CBCL-TRF onderzoek Boddaertcentra 1996. Gegevens over opname en vertrek. Utrecht, the Netherlands: VOG.

Kroes, M., Kalff, A. C., Kessels, A. G. H., Steyaert, J., Feron, F. J. M., van Someren, A. J. W. G. M., et al. (2001). Child psychiatric diagnoses in a population of Dutch school children aged 6 to 8 years. Journal of the American Academy of Child and Adolescent Psychiatry, 40, 1401-1409.

Lahey, B. B., Schwab-Stone, M., Goodman, S. H., Waldman, I. D., Canino, G., Rathouz, P. J., et al. (2000). Age and gender differences in oppositional behavior and conduct problems: A cross-sectional household study of middle childhood and adolescence. Journal of Abnormal Psychology, 109, 488-503.

Lahey, B. B., Van Hulle, C. A., Waldman, I. D., Rodgers, J. L., D’Onofrio, B. M., Pedlow, S., et al. (2006). Testing descriptive hypotheses regarding sex differences in the development of conduct problems and delinquency. Journal of Abnormal Child Psychology, 34, 737-755.

Laird, R. D., Pettit, G. S., Bates, J. E., \& Dodge, K. A. (2003). Parents' monitoring-relevant knowledge and adolescents' delinquent behavior: Evidence of correlated developmental changes and reciprocal influences. Child Development, 74, 752-768.

Lanctôt, N., \& LeBlanc, M. (2002). Explaining deviance by adolescent females. Crime and Justice: A Review of Research, $29,113-202$.

Lavigne, J. V., Gibbons, R. D., Christoffel, K. K., Arend, R., Rosenbaum, D., Binns, H., et al. (1996). Prevalence rates and correlates of psychiatric disorders among preschool children. Journal of the American Academy of Child and Adolescent Psychiatry, 35, 204-214.

Lee, V. E., Burkam, D. T., Zimiles, H., \& Ladewski, B. (1994). Family-structure and its effect on behavioural and emotional problems in young adolescents. Journal of Research on Adolescence, 4, 405-437.

Lewis, D., Yeager, C., Cobham-Portorreal, C., \& Klein, N. (1991). A follow-up of female delinquents: Maternal contributions to the perpetuation of deviance. Journal of the American Academy of Child and Adolescent Psychiatry, 30, 197-201.

Lipsey, M. W., \& Derzon, J. H. (1998). Predictors of violence or serious delinquency in adolescence or early adulthood. In R. Loeber \& D. P. Farrington (Eds.), Serious and violent juvenile offenders. Risk factors and successful interventions (pp. 313338). Thousand Oaks, CA: Sage.

Loeber, R., \& Dishion, T. (1983). Early predictors of male delinquency: A review. Psychological Bulletin, 94, 68-99.

Loeber, R., Drinkwater, M., Yin, Y., Anderson, S. J., Schmidt, L. C., $\&$ Crawford, A. (2000). Stability of family interaction from ages 6 to 18. Journal of Abnormal Child Psychology, 28, 353-369.

Loeber, R., \& Farrington, D. P. (Eds.). (2001). Child delinquents: Development, intervention and service needs. Thousand Oaks, CA: Sage.
Loeber, R., \& Keenan, K. (1994). Interaction between conduct disorder and its comorbid conditions: Effects of age and gender. Clinical Psychology Review, 14, 497-523.

Loeber, R., \& Stouthamer-Loeber, M. (1986). Family factors as correlates and predictors of juvenile conduct problems and delinquency. Crime and Justice, 7, 29-149.

Lytton, H., \& Romney, D. M. (1991). Parents' differential socialization of boys and girls: A meta-analysis. Psychological Bulletin, 109, 267-296.

Maccoby, E. E. (1990). Gender and relationships: A developmental account. American Psychologist, 45, 513-520.

Maniadaki, K., Sonuga-Barke, E. J. S., \& Kakouros, E. (2003). Trainee nursery teachers' perceptions of disruptive behavior disorders; the effect of sex of child on judgments of typicality and severity. Child: Care, Health and Development, 29, 433440.

Margolin, G., \& Gordis, E. B. (2000). The effects of family and community violence on children. Annual Review of Psychology, $51,445-479$.

Maughan, B., Rowe, R., Messer, J., Goodman, R., \& Meltzer, H. (2004). Conduct disorder and oppositional defiant disorder in a national sample: Developmental epidemiology. Journal of Child Psychology and Psychiatry, 45, 609-621.

McCabe, K. M., Rodgers, C., Yeh, M., \& Hough, R. (2004). Gender differences in childhood onset conduct disorder. Development and Psychopathology, 16, 179-192.

McFadyen-Ketchum, S. A., Bates, J. E., Dodge, K. A., \& Pettit, G. S. (1996). Patterns of change in early childhood aggressivedisruptive behavior: Gender differences in predictions from early coercive and affectionate mother-child interactions. Child Development, 67, 2417-2433.

McGue, M., Elkins, I., Walden, B., \& Iacono, W. G. (2005). Perceptions of the parent-adolescent relationship: A longitudinal investigation. Developmental Psychology, 41, 971-984.

McLoyd, V. C., Cauce, A. M., Takeuchi, D., \& Wilson, L. (2000). Marital processes and parental socialization in families of color: A decade review of research. Journal of Marriage and the Family, 62, 1070-1093.

McNally, S., Eisenberg, N., \& Harris, J. D. (1991). Consistency and change in maternal child-rearing practices and values: A longitudinal study. Child Development, 62, 190-198.

Moffitt, T. E. (1993). Adolescence-limited and life-course-persistent antisocial behavior: A developmental taxonomy. Psychological Review, 100, 674-701.

Moffitt, T. E. (2005). The new look of behavioral genetics in developmental psychopathology: Gene-environment interplay in antisocial behaviors. Psychological Bulletin, 131, 533-554.

Moffitt, T. E., \& Caspi, A. (2001). Childhood predictors differentiate life-course persistent and adolescence-limited antisocial pathways among males and females. Development and Psychopathology, 13, 355-375.

Moffitt, T. E., Caspi, A., Rutter, M., \& Silva, P. A. (2001). Sex differences in antisocial behaviour: Conduct disorder, delinquency, and violence in the Dunedin longitudinal study. Cambridge, UK: Cambridge University Press.

National Center on Child Abuse and Neglect. (1996). Child maltreatment 1994: Reports from the states to the national center on child abuse and neglect. Washington DC: US Government Printing Office.

Odgers, C. L., Moffitt, T. M., Broadbent, J. M., Dickson, N., Hancox, R. J., Harrington, H., et al. (2008). Female and male antisocial trajectories: From childhood origins to adult outcomes. Development and Psychopathology, 20, 673-716.

Offord, D., Boyle, M., \& Racine, Y. (1989). Ontario child health study: Correlates of disorder. Journal of the American Academy of Child and Adolescent Psychiatry, 28, 856-860. 
Offord, D. R., Boyle, M. H., Racine, Y. A., Fleming, J. E., Cadman, D. T., Blum, H. M., et al. (1992). Outcome, prognosis and risk in a longitudinal follow-up study. Journal of the American Academy of Child and Adolescent Psychiatry, 31, 916-923.

Patrick, M. R., Snyder, J., Schrepferman, L. M., \& Snyder, J. (2005). The joint contribution of early parental warmth, communication and tracking, and early child conduct problems on monitoring in late childhood. Child Development, 76, 999-1014.

Patterson, G. R., Chamberlain, O., \& Reid, J. B. (1982). A comparative evaluation of a parent-training program. Behavior Therapy, 13, 638-650.

Patterson, G. R., \& Dishion, T. J. (1985). Contributions of families and peers to delinquency. Criminology, 23, 63-79.

Pettit, G. S., Laird, R. D., Dodge, K. A., Bates, J. E., \& Criss, M. M. (2001). Antecedents and behavior-problem outcomes of parental monitoring and psychological control in early adolescence. Child Development, 72, 583-598.

Pittman, L. D., \& Chase-Lansdale, P. L. (2001). African American adolescent girls in impoverished communities: Parenting style and adolescent outcomes. Journal of Research on Adolescence, $11,199-224$.

Prinzie, P., Onghena, P., Hellinckx, W., Grietens, H., Ghesquiere, P., \& Colpin, H. (2005). Direct and indirect relationships between parental personality and externalizing behaviour: The role of negative parenting. Psychologica Belgica, 45, 123-145.

Robins, L. (1986). The consequences of conduct disorder in girls. In D. Olweus, J. Block, \& M. Radke-Yarrow (Eds.), Development of antisocial and prosocial behavior: Research, theories and issues (pp. 385-414). Orlando, FL: Academic Press.

Romano, E., Tremblay, R. E., Vitaro, F., Zoccolillo, M., \& Pagani, L. (2001). Prevalence of psychiatric diagnoses and the role of perceived impairment: Findings from an adolescent community sample. Journal of Child Psychology and Psychiatry, 42, 451-461.

Rose, A. J., \& Rudolph, K. D. (2006). A review of sex differences in peer relationship processes: Potential trade-offs for the emotional and behavioral development of girls and boys. Psychological Bulletin, 132, 98-131.

Rothbaum, F., \& Weisz, J. R. (1994). Parental caregiving and child externalizing behavior in nonclinical samples: A meta-analysis. Psychological Bulletin, 116, 55-74.

Rutter, M., Giller, H., \& Hagell, A. (1998). Antisocial behavior by young people. New York, NY: Cambridge University Press.

Sagrestano, L. M., McCormick, S. H., Paikoff, R. L., \& Holmbeck, G. N. (1999). Pubertal development and parent-child conflict in low-income, urban, African American adolescents. Journal of Research on Adolescence, 9, 85-107.

Savin-Williams, R. C., \& Berndt, T. J. (1990). Friendship and peer relations. In S. S. Feldman \& G. R. Elliott (Eds.), At the threshold: The developing adolescent (pp. 277-307). Cambridge, MA: Harvard University Press.

Scaramella, L. V., Conger, R. D., \& Simons, R. L. (1999). Parental protective influences and gender-specific increases in adolescent internalizing and externalizing problems. Journal of Research on Adolescence, 9, 111-141.

Schaeffer, C. M., Petras, H., Ialongo, N., Masyn, K. E., Hubbard, S., Poduska, J., et al. (2006). A comparison of girls' and boys' aggressive-disruptive behavior trajectories across elementary school: Prediction to young adult antisocial outcomes. Journal of Consulting and Clinical Psychology, 74, 500-510.

Serbin, L., Moskowitz, D., Schwartzman, A., \& Ledingham, J. (1991). Aggressive, withdrawn, and aggressive/withdrawn children in adolescence: Into the next generation. In D. Pepler \& K. Rubin (Eds.), The development and treatment of childhood aggression (pp. 55-70). Hillsdale, NJ: Lawrence Erlbaum.

Shumow, L., Vandell, D. L., \& Posner, J. K. (1998). Harsh, firm, and permissive parenting in low-income families: Relations to children's academic achievement and behavioral adjustment. Journal of Family Issues, 19, 483-507.

Silverthorn, P., \& Frick, P. J. (1999). Developmental pathways to antisocial behavior: The delayed-onset pathway in girls. Development and Psychopathology, 11, 101-126.

Silverthorn, P., Frick, P. J., \& Reynolds, R. (2001). Timing of onset and correlates of severe conduct problems in adjudicated girls and boys. Journal of Psychopathology and Behavioral Assessment, 23, 171-181.

Simonoff, E., Pickles, A., Meyer, J. M., Silberg, J. L., Maes, H. H., Loeber, R., et al. (1997). The Virginia twin study of adolescent behavioral development: Influence of age, sex, and impairment on rates of disorder. Archives of General Psychiatry, 54, 801-808.

Simons, R. L., Johnson, C., Beaman, J., Conger, R. D., \& Whitbeck, L. B. (1996). Parents and peer group as mediators of the effect of community structure on adolescent problem behavior. American Journal of Community Psychology, 24, 145-171.

Simons, R. L., Whitbeck, L. B., Conger, R. D., \& Conger, K. J. (1991). Parenting factors, social skills, and value commitments as precursors to school failure, involvement with deviant peers, and delinquent behavior. Journal of Youth and Adolescence, 20, 645-664.

Smith, H., \& Thomas, S. (2000). Violent and non-violent girls: Contrasting perceptions of anger experiences, school, and relationships. Issues in Mental Health Nursing, 21, 547-575.

Snyder, J. J., \& Patterson, G. R. (1995). Individual differences in social aggression: A test of a reinforcement model of socialization in the natural environment. Behavior Therapy, 63, 12661281.

Snyder, J., Schrepferman, L., Oeser, J., Patterson, G., Stoolmiller, M., Johnson, K., et al. (2005). Deviancy training and association with deviant peers in young children: Occurrence and contribution to early-onset conduct problems. Development and Psychopathology, 17, 397-413.

Stattin, H., \& Kerr, M. (2000). Parental monitoring: A reinterpretation. Child Development, 71, 1072-1085.

Steinberg, L., Blatt-Eisengart, I., \& Caufmann, E. (2006). Patterns of competence and adjustment among adolescents from authoritative, authoritarian, indulgent, and neglectful homes: A replication in a sample of serious juvenile offenders. Journal of Research on Adolescence, 16, 47-58.

Storvoll, E. E., \& Wichstrom, L. (2002). Do the risk factors associated with conduct problems in adolescents vary according to gender? Journal of Adolescence, 25, 183-202.

Stouthamer-Loeber, M., Loeber, R., Wei, E., Farrington, D. P., \& Wikström, P. H. (2002). Risk and promotive effects in the explanation of persistent serious delinquency in boys. Development and Psychopathology, 13, 941-955.

Straus, M. A., \& Stewart, J. H. (1999). Corporal punishment by American parents: National data on prevalence, chronicity, severity, and duration, in relation to child and family characteristics. Clinical Child and Family Review, 2, 55-70.

Svensson, R. (2003). Gender differences in adolescent drug use: The impact of parental monitoring and peer deviance. Youth \& Society, 34, 300-329.

Tremblay, R. E. (2000). The development of aggressive behaviour during childhood: What have we learned in the past century? International Journal of Behavioral Development, 24, 129-141.

Tremblay, R. E. (2001). The development of physical aggression during childhood and the prediction of later dangerousness. In G.-F. Pinard \& L. Pagani (Eds.), Clinical assessment of dangerousness: Empirical contributions (pp. 47-65). New York, NY: Cambridge University Press.

Tremblay, G., Saucier, J., \& Tremblay, R. E. (2004). Identity and disruptiveness in boys: Longitudinal perspectives. Child and Adolescent Social Work Journal, 21, 387-404. 
Vandewater, E. A., \& Lansford, J. E. (2005). A family process model of problem behaviors in adolescents. Journal of Marriage and Family, 67, 100-109.

Vitaro, F., Tremblay, R. E., \& Bukowski, W. M. (2001). Friends, friendships, and conduct disorders. In J. Hill \& B. Maughan (Eds.), Conduct disorders in childhood and adolescence. Cambridge child and adolescent psychiatry (pp. 346-378). New York: Cambridge University Press.

Wall, A. E., \& Barth, R. P. (2005). Aggressive and delinquent behavior of maltreated adolescents: Risk factors and gender differences. Stress, Trauma and Crisis, 8, 1-24.

Webb, J. A., Bray, J. H., Getz, J. G., \& Adams, G. (2002). Gender, perceived parental monitoring, and behavioral adjustment: Influences on adolescent alcohol use. American Journal of Orthopsychiatry, 72, 392-400.

Webster-Stratton, C. (1996). Early-onset conduct problems: Does gender make a difference? Journal of Consulting and Clinical Psychology, 64, 540-551.

Widom, C. (1978). Towards an understanding of female criminality. In B. A. Mahler (Ed.), Progress in experimental personality research (pp. 245-308). New York: Academic Press.

Wikström, \& Loeber, R. (2000). Do disadvantaged neighborhoods cause well-adjusted children to become adolescent delinquents?
A study of male juvenile serious offending, individual risk and protective factors, and neighbourhood context. Criminology, 38, $1109-1142$.

Woolfenden, S. R., Williams, K., \& Peat, J. K. (2002). Family and parenting interventions for conduct disorder and delinquency: A meta-analysis of randomized controlled trials. Archives of Disease in Childhood, 86, 251-256.

Xie, H., Cairns, R. B., \& Cairns, B. D. (2002). The development of social aggression and physical aggression: A narrative analysis of interpersonal conflicts. Aggressive Behavior, 28, 341-355.

Yoshikawa, H. (1994). Prevention as cumulative protection: Effects of early family support and education on chronic delinquency and its risks. Psychological Bulletin, 115, 28-54.

Zahn-Waxler, C., \& Polanichka, N. (2004). All things interpersonal. Socialization and female aggression. In M. Putallaz \& K. L. Bierman (Eds.), Aggression, antisocial behavior, and violence among girls: A developmental perspective (pp. 48-68). New York: The Guilford Press.

Zoccolillo, M. (1993). Gender and the development of conduct disorder. Development and Psychopathology, 5, 65-78. 